\title{
ColonizaçÃo Micorrízica e Atividade de Fosfatases Ácidas na Rizosfera de Cultivares de Cana-De-Açúcar após APlicaÇão de HERBICIDAS ${ }^{1}$
}

\author{
Mycorrhizal Colonization and Acid Phosphatase Activity in the Rhizosphere of Sugarcane \\ Cultivars After Herbicide Application
}

\author{
REIS, M.R. ${ }^{2}$, TIRONI, S.P. ${ }^{2}$, COSTA, M.D. ${ }^{3}$, SILVA, M.C.S. ${ }^{4}$, FERREIRA, E.A. ${ }^{5}$, BELO, A.F..$^{2}$, \\ BARBOSA, M.H.P. ${ }^{6}$ eSILVA, A.A. ${ }^{6}$
}

\begin{abstract}
RESUMO - Objetivou-se com este trabalho avaliar o impacto de herbicidas na colonização micorrizica e na atividade de fosfatases ácidas na rizosfera dos cultivares de cana-de-açúcar RB867515 e SP80-1816. O experimento foi conduzido em campo, em sistema de cultivo convencional, com espaçamento de $1,4 \mathrm{~m}$ e 18 gemas $\mathrm{m}^{-1}$. Utilizou-se o delineamento em blocos casualizados, em esquema fatorial $2 \times 5$, com quatro repetições, sendo o primeiro fator constituído por dois cultivares de cana-de-açúcar (RB867515 e SP80-1816) e o segundo por quatro herbicidas (ametryn, $2.000 \mathrm{~g} \mathrm{ha}^{-1}$; trifloxysulfuron-sodium, 22,5 $\mathrm{g} \mathrm{ha}^{-1}$; ametryn + trifloxysulfuron-sodium, $1.463+37,5 \mathrm{~g} \mathrm{ha}^{-1}$, e sulfentrazone, $750 \mathrm{~g} \mathrm{ha}^{-1}$ ), mais uma testemunha sem aplicação de herbicida. A aplicação dos herbicidas foi realizada quando a cultura encontrava-se com três a quatro folhas. O sistema radicular e o solo rizosférico de cana-deaçúcar foram coletados para avaliação da colonização micorrízica e atividade de fosfatases aos 7, 14 e 28 dias após a aplicação dos herbicidas (DAH). Os herbicidas não interferiram na atividade das fosomonoesterases ácidas nas épocas avaliadas. O cultivar RB867515 apresentou maior colonização micorrízica (22,5 e 27,0\%), em comparação à testemunha, sem aplicação de herbicidas, aos 7 e $14 \mathrm{DAH}$, respectivamente. Aos $7 \mathrm{DAH}$, constatou-se menor valor de colonização (11,50\%) para o cultivar RB86-7515 tratado com trifloxysulfuron-sodium + ametryn. O herbicida trifloxysulfuron-sodium estimulou a colonização micorrízica no cultivar SP80-1816 aos 14 DAH (46,3\%). Ambos os cultivares avaliados apresentaram maiores valores de colonização quando tratados com ametryn, aos $28 \mathrm{DAH}$. De modo geral, constatou-se incremento da colonização micorrízica do sistema radicular em função do tempo. A colonização micorrizica foi distinta entre os cultivares e os herbicidas usados.
\end{abstract}

Palavras-chave: trifloxysulfuron-sodium, ametryn, sulfentrazone, micorrização.

\begin{abstract}
The objective of this work was to evaluate the impact of herbicides on the mycorrhizal colonization and rhizospheric acid phosphatase activity of sugarcane cultivars RB86-7515 and SP80-1816. The experiment was conducted in the field in a conventional tillage system, with $1.4 \mathrm{~m}$ spacing between plants and 18 buds $\mathrm{m}^{-1}$. A randomized block design was used following a $2 \times 5$ factorial, with four replications, in which the first factor corresponded to two sugarcane cultivars (RB867515 and SP80-1816) and the second to four herbicides (ametryn, 2,000 $\mathrm{g} \mathrm{ha-1}$; trifloxysulfuron-sodium, $22.5 \mathrm{~g} \mathrm{ha}^{-1}$; ametryn + trifloxysulfuron-sodium, 1,463 + $37.5 \mathrm{~g} \mathrm{ha-1}$; sulfentrazone, $750 \mathrm{~g} \mathrm{ha}^{-1}$ ). A control treatment without herbicide application was also included. Herbicide application was performed when sugarcane plants presented three to four leaves. The root system and the rhizospheric soil were collected for evaluation of mycorrhizal colonization and acid phosphatase activity at 7, 14, and 28 days after herbicide application (DHA). The herbicides tested did not affect acid phosphatase activity in the rhizosphere soil. RB897515 presented higher
\end{abstract}

Recebido para publicação em 6.4.2009 e na forma revisada em 11.12.2009.

2 Engo-Agr ${ }^{\circ}$, Doutor em Fitotecnia - DFT/UFV, Pós-Doutorando do PNPD/CAPES, Universidade Federal de Tocantins - UFT, Gurupi-TO, Tel.:(63) - 8136-0063, <reisagro@yahoo.com.br>; ${ }^{3}$ D.Sc., Professor do Dep. de Microbiologia, Universidade Federal de Viçosa - MBI/UFV, Av. P.H. Rolphs, Campus Universitário, 36570-000 Viçosa-MG; ${ }^{4}$ Bióloga, Doutoranda em Microbiologia Agrícola - MBI/UFV; ${ }^{5}$ Engo-Agr ${ }^{0}$, D.Sc., Pós-Doutor em Fitotecnia - DFT/UFV; ${ }^{6}$ D. Sc., Professor - DFT/UFV. 
mycorrhizal colonization, 22.5 and 27.0\%, compared to the control treatment at 7 and 14 DHA, respectively. After $7 \mathrm{DHA}$, the lowest mycorrhizal colonization, 11.5\%, was recorded for cultivar RB867515 treated with trifloxysulfuron-sodium + ametryn. Trifloxysulfuron-sodium stimulated mycorrhizal colonization in the cultivar SP80-1816 at 14 DHA (46.3\%). Both cultivars presented higher values of mycorrhizal colonization in the treatments with ametryn at $28 \mathrm{DHA}$. An increase in mycorrhizal colonization was generally observed along the cultivation period. Mycorrhizal colonization was distinct among the cultivars and herbicides tested.

Keywords: trifloxysulfuron-sodium, ametryn, sulfentrazone, mycorrhization.

\section{INTRODUÇÃO}

A cana-de-açúcar destaca-se como a terceira cultura em área cultivada e como a segunda em utilização de herbicidas no Brasil, sendo cerca de $50 \%$ da produção direcionada para a indústria alcooleira (CONAB, 2009; SINDAG, 2009). A produção de álcool combustivel tem sido bastante incentivada pelo governo; no entanto, os impactos ambientais da expansão de novas áreas cultivadas com canade-açúcar têm sido negligenciados. Algumas práticas que objetivam minimizar o impacto desse cultivo devem ser adotadas, a exemplo de técnicas de manejo que beneficiem a interação da cultura com os microrganismos do solo.

Os fungos micorrízicos arbusculares (FMAs) são simbiontes obrigatórios pertencentes à ordem Glomerales, capazes de se associar às raízes de cerca de $80 \%$ das espécies vegetais conhecidas (Sylvia, 2005). Os FMAs destacamse entre os microrganismos do solo que interagem naturalmente com as raízes de cana-deaçúcar sob diferentes condições ambientais (Reis et al., 1999), pois eles proporcionam às plantas maior capacidade de exploração do solo. Também, as plantas associadas a esses fungos são beneficiadas pela maior absorção de fósforo $(\mathrm{P})$, de nitrogênio $(\mathrm{N})$ e de outros nutrientes do solo, aumentando a resistência a doenças e diminuindo as consequências de estresses causados por fatores adversos, a exemplo do déficit hídrico (Sylvia, 2005). Os FMAs podem contribuir também para a agregação de partículas do solo (Berbara et al., 2006). Segundo Miyauchi et al. (2008), os FMAs aumentaram a massa, o comprimento total e específico, a superficie total e a quantidade de pelos radiculares em genótipos de milho. Essa associação também promoveu a proteção contra estresse salino em plantas de milho, aumentando a eficiência de utilização da água (Sheng et al., 2008). A maior absorção de água e nutrientes é de fundamental importância para a nutrição mineral de plantas, principalmente em condições tropicais, em que os solos apresentam baixos teores de $\mathrm{P}$ disponiveis e regime hídrico anual desuniforme (Novais et al., 2007).

Os FMAs possuem a capacidade de promover a solubilização de nutrientes inorgânicos através da produção e liberação de agentes solubilizadores - em particular, o oxaloacetato (Landeweert et al., 2001). Esses microrganismos também estimulam a colonização das raízes por bactérias diazotróficas, potencializando a fixação biológica do N (Miyauchi et al., 2008).

Outra característica importante dos FMAs e de outros microrganismos do solo é a capacidade de secretar fosfomonoesterases, que irão atuar na mineralização de fosfato orgânico do solo. Uma vez que em solos intemperizados o fosfato orgânico é a principal fonte de fósforo para a nutrição vegetal, torna-se de grande importância a atividade dessas enzimas no solo (Rheinheimer et al., 2008).

No entanto, alguns fatores influenciam as associações micorrízicas, como a textura do solo; a calagem (Carrelho et al., 2007); o sistema de cultivo (Dawo et al., 2009); a contaminação do solo com metais pesados (Andrade \& Silveira, 2008); as queimadas realizadas para a colheita de cana-de-açúcar (Reis et al., 1999); e os agrotóxicos, a exemplo dos herbicidas (Abd-Alla et al., 2000; Santos et al., 2006; Vieira et al., 2007), com respostas variadas em função do composto químico e da espécie de planta em questão (Bethlenfalvay et al., 1996). 
O herbicida sulfentrazone, aplicado na préemergência da cultura da soja, reduziu a colonização por FMAs na proporção de 48 e $37 \%$ aos 24 e 75 dias após a emergência das plântulas, respectivamente (Vieira et al., 2007). Contudo, Santos et al. (2006) constataram menor colonização micorrízica em feijoeiro cultivado em sitema convencional até 12 dias após a aplicação dos herbicidas fomesafen e fluazifop- $p$-butyl, ambos aplicados isolados ou em mistura. O herbicida glyphosate, aplicado no solo em pré-semeadura da soja, não influenciou a colonização por FMAs até a dose de $10 \mathrm{~L} \mathrm{ha}^{-1}$. Entretanto, testes in vitro realizados com esse produto detectaram inibições da germinação e do crescimento dos tubos germinativos dos esporos Gigaspora margarita, Glomus etunicatum e Scutellospora heterogama (Malty et al., 2006).

Nos cultivos da cana-de-açúcar é comum o uso de agrotóxicos, principalmente os herbicidas, utilizados no manejo das plantas daninhas (Christoffoleti et al., 2006). Os herbicidas mais usados nessa cultura são de longo efeito residual no solo, com o objetivo de controlar as plantas daninhas ao longo do tempo, já que a cana-de-açúcar apresenta desenvolvimento inicial lento e habilidade competitiva reduzida (Procópio et al., 2003).

Entre os herbicidas recomendados para a cana-de-açúcar, encontram-se o ametryn e o trifloxysulfuron-sodium, que atuam, respectivamente, na inibição do fotossistema II e da enzima acetolactato sintase (ALS). Esses herbicidas são comercializados em mistura, para aumentar o espectro de controle, sendo o comportamento do produto no ambiente pouco conhecido (Rodrigues \& Almeida, 2005). Outro herbicida comumente utilizado é o sulfentrazone, que atua na inibição da enzima protoporfirinogênio oxidase (Silva et al., 2007) e apresenta longo efeito residual no solo. Resíduos desse herbicida foram detectados no solo por até 640 dias após uma aplicação em dois anos consecutivos em lavouras de canade-açúcar (Vivian et al., 2006).

Os estudos envolvendo herbicidas, de forma geral, têm dado ênfase apenas à eficiência no controle das plantas daninhas (Pires et al., 2005), com poucos relatos sobre os efeitos desses produtos nos microrganismos do solo. Assim, objetivou-se com este trabalho avaliar os efeitos dos herbicidas trifloxysulfuronsodium, ametryn, trifloxysulfuron-sodium + ametryn e sulfentrazone sobre a colonização micorrizica arbuscular e a atividade de fosfatases ácidas do solo rizosférico das cultivares de cana-de-açúcar SP80-1816 e RB867515.

\section{MATERIAL E MÉTODOS}

O experimento foi conduzido na Estação Experimental da Horta Nova, pertencente à Universidade Federal de Viçosa (UFV), Viçosa, MG, durante os meses de novembro de 2008 a janeiro de 2009. O plantio da cana-de-açúcar foi realizado em um Argissolo VermelhoAmarelo (Embrapa, 2006), no sistema de cultivo convencional, com espaçamento entre os sulcos de 1,40 m e densidade de 18 gemas $\mathrm{m}^{-1}$. A adubação foi efetuada no sulco de plantio, na proporção de $500 \mathrm{~kg} \mathrm{ha}^{-1}$ da formulação NPK 08-28-16, de acordo com resultados da análise do solo (Tabela 1) e das recomendações para cultura (CFSEMG, 1999).

O delineamento experimental foi o de blocos casualizados com quatro repetições, sendo as parcelas constituídas por seis linhas de 3,0 m de comprimento, com área total de $25,2 \mathrm{~m}^{2}(8,4 \times 3,0 \mathrm{~m})$. Os tratamentos foram alocados em esquema fatorial $2 \times 5$, sendo o primeiro fator representado pelas cultivares de cana-de-açúcar, RB867515 e SP80-1816, e o segundo, pelos herbicidas Metrimex $500 \mathrm{SC}^{\circledR}$ (ametryn, $2.000 \mathrm{~g} \mathrm{ha}^{-1}$ ), Envoke ${ }^{\circledR}$ (trifloxysulfuron-sodium, 22,5 $\mathrm{g} \mathrm{ha}^{-1}$ ), Krismat ${ }^{\circledR}$ (trifloxysulfuron-sodium + ametryn, 37,5 + $1.463 \mathrm{~g} \mathrm{ha}^{-1}$ ) e Boral $500 \mathrm{SC}^{\circledR}$ (sulfentrazone, $750 \mathrm{~g} \mathrm{ha}^{-1}$ ), além de uma testemunha sem aplicação de herbicida.

A aplicação dos herbicidas foi feita quando as plantas se encontravam com três a quatro folhas completamente expandidas. Para isso, utilizou-se pulverizador costal pressurizado a $\mathrm{CO}_{2}$, munido com barra de aplicação com três pontas de pulverização da série TT 110.02 , espaçadas de $0,5 \mathrm{~m}$, calibrado para aplicar $150 \mathrm{~L} \mathrm{ha}^{-1}$ de calda.

A coleta de amostras do sistema radicular e do solo rizosférico da cultura foram realizadas aos 7, 14 e 28 dias após a aplicação dos herbicidas (DAH). O sistema radicular foi lavado e posteriormente amostrado, retirando-se fragmentos de, aproximadamente, $1 \mathrm{~cm}$ de 
Tabela 1 - Características químicas e físicas do solo, de amostras coletadas de 0 a $10 \mathrm{~cm}$ de profundidade, de lavouras de cana-deaçúcar (cana-planta) em estádio vegetativo, com três folhas completamente expandidas. Viçosa-MG, 2008

\begin{tabular}{|c|c|c|c|c|c|c|c|c|c|c|c|c|}
\hline \multicolumn{13}{|c|}{ Características químicas ${ }^{\underline{1}}$} \\
\hline $\mathrm{pH}$ & $\mathrm{P}$ & $\mathrm{K}^{+}$ & $\mathrm{Ca}^{2+}$ & $\mathrm{Mg}^{2+}$ & $\mathrm{Al}^{3+}$ & $\mathrm{H}+\mathrm{A}$ & SB & $\mathrm{CTC}(\mathrm{t})$ & CTC (T) & $\mathrm{V}$ & $\mathrm{m}$ & $\mathrm{MO}$ \\
\hline$\left(\mathrm{H}_{2} \mathrm{O}\right)$ & \multicolumn{2}{|c|}{$\left(\mathrm{mg} \mathrm{dm}^{-3}\right)$} & \multicolumn{7}{|c|}{$\left(\mathrm{cmol}_{\mathrm{c}} \mathrm{dm}^{-3}\right)$} & \multicolumn{2}{|c|}{$(\%)$} & $\left(\right.$ dag kg $\left.{ }^{-1}\right)$ \\
\hline 6,0 & 7,4 & 168 & 4,2 & 0,7 & 0,0 & 4,46 & 5,33 & 5,33 & 9,79 & 54 & 0 & 2,4 \\
\hline \multicolumn{13}{|c|}{ 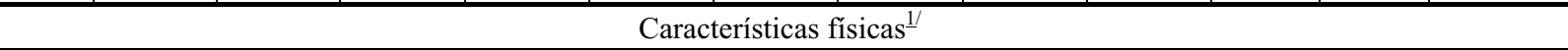 } \\
\hline & & & Silte & & Areia $g_{1}$ & & Arei & Fina & \multirow{2}{*}{\multicolumn{4}{|c|}{ Classificação textural }} \\
\hline \multicolumn{9}{|c|}{$(\%)$} & & & & \\
\hline & & & 32 & & 7 & & & & \multicolumn{4}{|c|}{ Argiloso } \\
\hline
\end{tabular}

1/ Análise realizada no Laboratório de Análise de Solos Viçosa Ltda; CTC (T): Capacidade da troca de cátions (pH 7); CTC (t): capacidade de troca de cátions efetiva; V: saturação de bases; m: saturação de alumínio; MO: matéria orgânica.

comprimento das raizes finas, de forma que representasse todo o sistema radicular. As raízes amostradas foram clarificadas com $\mathrm{KOH}$ (10\%) e coradas com azul de tripano em lactoglicerol 0,05\% (Phillips \& Hayman 1970). Para avaliação da colonização micorrízica, utilizou-se a técnica descrita por Giovannetti $\&$ Mosse (1980).

O solo rizosférico foi considerado como o solo remanescente após breve agitação do sistema radicular das plantas de cana-deaçúcar, sendo ele coletado após agitação mais intensa. As amostras do solo rizosférico de cana-de-açúcar foram utilizadas para determinação de atividade de fosfomonoesterases ácidas, conforme o método proposto por Tabatabai \& Bremmer (1969). Alíquotas de um grama de solo foram transferidas para tubos de ensaio contendo $4 \mathrm{~mL}$ da solução-tampão ácida (pH 6,5), constituída por: tris(hidroximetil) aminometano (THAM) (12,1 g), ácido maleico $(11,6 \mathrm{~g})$, ácido cítrico $(14,0 \mathrm{~g})$, ácido bórico (6,3 g), hidróxido de sódio (20 g) e água desionizada (q.s.p. 1 L). Aos tubos com solo foram adicionados $0,2 \mathrm{~mL}$ de tolueno e $1 \mathrm{~mL}$ da solução de $p$-nitrofenilfosfato dissódico tetraidratado $\left(\mathrm{C}_{6} \mathrm{H}_{4} \mathrm{NNaO}_{6} \mathrm{P} .4 \mathrm{H}_{2} \mathrm{O}\right), 0,05 \mathrm{moL} \mathrm{L}^{-1}$, substrato da enzima fosfatase. Os tubos foram incubados a $37^{\circ} \mathrm{C}$ por uma hora. Após a incubação, foram adicionados $1 \mathrm{~mL}$ de $\mathrm{CaCl}_{2}$ $\left(0,5 \mathrm{~mol} \mathrm{~L}^{-1}\right)$ e $4 \mathrm{~mL}$ de $\mathrm{NaOH}\left(0,5 \mathrm{~mol} \mathrm{~L}^{-1}\right)$ a cada tubo, submetendo-os à agitação e filtragem por gravidade em papel-filtro Whatman no 42 . A concentração de $p$-nitrofenol no filtrado foi determinada por espectrofotometria a $420 \mathrm{~nm}$, sendo os resultados expressos em $\mu \mathrm{g} p$-nitrofenol $\mathrm{g}^{-1} \mathrm{~h}^{-1}$.

Os dados obtidos foram submetidos à análise de variância. Sendo o valor de F significativo, aplicou-se o teste de Tukey para comparação das médias dos tratamentos. Todos os testes foram efetuados a $5 \%$ de probabilidade de significância.

\section{RESUTADOS E DISCUSSÃO}

A colonização micorrizica dos sistemas radiculares dos cultivares RB867515 e SP80-1816 não diferiu, em média, independentemente da aplicação ou não de herbicidas, aos 7 e 14 dias após a aplicação dos herbicidas (DAH). Já aos 28 DAH, observou-se, em média, menor colonização micorrízica no cultivar RB867515 (Tabela 2). Variação na colonização micorrízica entre cultivares foi também relatada para plantas de milho, sendo as maiores colonizações relacionadas ao maior diâmetro das raízes (Miyauchi et al., 2008).

Aos 7 DAH, excetuando-se os resultados obtidos para a mistura trifloxysulfuron-sodium + ametryn, não houve diferença na colonização micorrízica dos cultivares avaliados (Tabela 2). Esses resultados evidenciam maior efeito negativo da mistura dos herbicidas trifloxysulfuron-sodium + ametryn, possivelmente, devido a efeitos tóxicos sinérgicos A aplicação do sulfentrazone em pré-emergência da cultura da soja reduziu a 
colonização micorrízica do sistema radicular, com maiores efeitos logo após a aplicação (Vieira et al., 2007). Essa interferência foi atribuída ao menor crescimento das plantas tratadas com o herbicida. Santos et al. (2006) observaram menor colonização de FMAs no sistema radicular de feijoeiro em cultivo convencional, até os 12 dias após a aplicação dos herbicidas fomesafen e fluazifop- $p$-butyl, em aplicações isoladas ou em mistura.

Avaliando o efeito de cultivares na colonização micorrízica aos $14 \mathrm{DAH}$, observou-se maior colonização do sistema radicular do cultivar RB867515, comparativamente com a SP80-1816. Em ambos os cultivares houve maior colonização micorrízica na ausência de herbicidas. No entanto, os tratamentos com o trifloxysulfuron-sodium proporcionaram maior colonização micorrízica para SP80-1816; já os demais tratamentos não demonstraram diferenças significativas nessa época (Tabela 2). A ação desse herbicida pode resultar em maior estimulo à micorrização, porém as causas são ainda desconhecidas. Reis et al. (2008) e Tironi (2009) constataram efeito estimulante do trifloxysulfuron-sodium sobre microrganismos solubilizadores de fosfato inorgânico do solo rizosférico da cana-de-açúcar; esse efeito foi atribuído, em parte, às mudanças no padrão de exsudação radicular do cultivar, alterando sua interação com os microrganismos do solo. Quanto aos efeitos negativos, Rejon et al. (1997) observaram inibição da

Tabela 2 - Colonização micorrízica do sistema radicular de cultivares de cana-de-açúcar SP80-1816 e RB867515 aos 7, 14 e 28 dias após a aplicação de herbicidas (DAH). Viçosa-MG, 2008

\begin{tabular}{|c|c|c|c|}
\hline \multirow{3}{*}{ Herbicida } & \multicolumn{3}{|c|}{ Cultivar } \\
\hline & SP80-1816 & RB867515 & Média \\
\hline & \multicolumn{3}{|c|}{$(\%)$} \\
\hline \multicolumn{4}{|c|}{$7 \mathrm{DAH}$} \\
\hline Testemunha sem herbicida & $13,75 \mathrm{aB}^{5 /}$ & $22,50 \mathrm{aA}$ & $18,13 \mathrm{~b}$ \\
\hline Trifloxysulfuron-sodium $^{1 /}$ & $20,25 \mathrm{aA}$ & $21,75 \mathrm{abA}$ & $21,00 \mathrm{ab}$ \\
\hline Ametryn $^{2 /}$ & $21,25 \mathrm{aA}$ & $27,00 \mathrm{aA}$ & $24,13 \mathrm{a}$ \\
\hline Trifloxysulfuron-sodium + ametryn $^{3 /}$ & $19,50 \mathrm{aA}$ & $11,50 \mathrm{bB}$ & $15,50 \mathrm{~b}$ \\
\hline Sulfentrazone $^{4 / /}$ & $15,50 \mathrm{aA}$ & $20,75 \mathrm{abA}$ & $18,13 \mathrm{ab}$ \\
\hline Média & $18,05 \mathrm{~A}$ & $20,07 \mathrm{~A}$ & \\
\hline $\mathrm{CV}(\%)$ & & 25,02 & \\
\hline \multicolumn{4}{|c|}{$14 \mathrm{DAH}$} \\
\hline Testemunha sem herbicida & $14,75 \mathrm{bB}$ & $27,00 \mathrm{aA}$ & $20,88 \mathrm{~b}$ \\
\hline Trifloxysulfuron-sodium ${ }^{1 /}$ & $46,25 \mathrm{aA}$ & $22,75 \mathrm{aB}$ & $34,50 \mathrm{a}$ \\
\hline Ametryn $^{2 /}$ & $24,75 \mathrm{bA}$ & $20,75 \mathrm{aA}$ & $22,75 \mathrm{~b}$ \\
\hline Trifloxysulfuron-sodium + ametryn $^{3 /}$ & $24,00 \mathrm{bA}$ & $20,50 \mathrm{aA}$ & $22,25 \mathrm{~b}$ \\
\hline Sulfentrazone $e^{4 /}$ & $16,00 \mathrm{bA}$ & $22,75 \mathrm{aA}$ & $19,38 \mathrm{~b}$ \\
\hline Média & $25,15 \mathrm{~A}$ & $22,75 \mathrm{~A}$ & \\
\hline $\mathrm{CV}(\%)$ & & 30,94 & \\
\hline \multicolumn{4}{|c|}{$28 \mathrm{DAH}$} \\
\hline Testemunha sem herbicida & $25,25 \mathrm{bA}$ & $16,25 \mathrm{bA}$ & $20,75 \mathrm{c}$ \\
\hline Trifloxysulfuron-sodium $^{1 /}$ & $33,75 \mathrm{abA}$ & $25,75 \mathrm{bA}$ & $29,75 \mathrm{bc}$ \\
\hline Ametryn $^{2 /}$ & $37,75 \mathrm{abB}$ & $50,75 \mathrm{aA}$ & $44,25 \mathrm{a}$ \\
\hline Trifloxysulfuron-sodium + ametryn $^{3 /}$ & $43,75 \mathrm{aA}$ & $22,75 \mathrm{bB}$ & $33,25 \mathrm{~b}$ \\
\hline Sulfentrazone $e^{4 /}$ & $31,00 \mathrm{abA}$ & $27,00 \mathrm{bA}$ & $29,00 \mathrm{bc}$ \\
\hline Média & $34,30 \mathrm{~A}$ & $28,50 \mathrm{~B}$ & \\
\hline $\mathrm{CV}(\%)$ & \multicolumn{3}{|c|}{20,55} \\
\hline
\end{tabular}

${ }^{1 /}$ Envoke $^{\circledR} ;{ }^{2 /}$ Metrimex $500 \mathrm{SC}^{\circledast} ;{ }^{3 /}$ Krismat $^{\circledR} ;{ }^{4 /}$ Boral $500 \mathrm{SC}^{\circledR} ; \stackrel{5}{5}$ Médias seguidas de mesmas letras, minúsculas nas colunas e maiúsculas nas linhas, não diferem entre si pelo teste de Tukey a $5 \%$ de probabilidade para cada época de coleta. 
colonização por Glomus deserticola com a aplicação do herbicida diclofop no sistema radicular de trigo somente em aplicações superiores a cem vezes a dose recomendada. No entanto, com doses de até mil vezes a recomendada, o herbicida não influenciou a colonização do sistema radicular do azévem por espécie fúngica.

$\mathrm{Na}$ avaliação aos $28 \mathrm{DAH}$, os herbicidas ametryn e trifloxysulfuron-sodium propiciaram maiores colonizações micorrízicas nos cultivares RB867515 e a SP80-1816, em relação aos demais tratamentos com herbicidas (Tabela 2). No cultivar SP80-1816, a maior colonização de FMA foi observada no tratamento com trifloxysulfuron-sodium + ametryn em relação à testemunha, porém não diferiu dos demais tratamentos com herbicidas (Tabela 2). O ametryn proporcionou em média maior micorrização, independentemente dos cultivares, aos 7 e 28 DAH. Avaliando a interação cultivar x herbicida, observou-se maior colonização micorrízica no cultivar RB867515 tratado com ametryn aos 28 DAH (Tabela 2). Esses resultados demonstram efeitos diferenciados de cada herbicida sobre os cultivares, com prováveis mudanças no metabolismo do sistema radicular, que afetam a interação da planta com os FMAs. A maior sintese e exsudação radiculares de aminoácidos e açúcares é normalmente influenciada por condições de estresse (Bertin et al., 2003), como temperaturas extremas, seca e exposição a raios ultravioleta (Pramanik et al., 2000). Sugere-se que a aplicação dos herbicidas possa constituir situação de estresse, levando a alterações características nos exsudatos radiculares da cana-de-açúcar.

Para o cultivar SP80-1816, observou-se aumento da colonização micorrízica em função do tempo. As maiores percentagens foram observadas aos 28 DAH em todos os tratamentos, exceto naquele com trifloxysulfuronsodium, o qual apresentou maior porcentagem de colonização micorrízica aos $14 \mathrm{DAH}$ (Tabela 3).

A colonização micorrízica do cultivar RB867515 não foi alterada ao longo do tempo nos tratamentos avaliados, exceto o herbicida ametryn e a mistura herbicida trifloxysulfuronsodium + ametryn. Ambos os herbicidas proporcionaram maiores porcentagens de colonização micorrízica com o passar do tempo, sendo os maiores valores observados na última época, avaliada aos $28 \mathrm{DAH}$ (Tabela 4). Nesta época, todos os tratamentos apresentaram maiores valores para a colonização micorrízica em relação às épocas avaliadas aos 7 e aos 14 DAH. Esses resultados evidenciam a diferenciação entre os herbicidas quando aplicados sobre o cultivar RB867515; alguns não alteraram a associação ao longo do tempo entre a cultura e os FMAs, e outros apresentaram efeitos benéficos para a associação. Esse fato pode estar relacionado principalmente com o mecanismo de ação do herbicida e também com as características intrinsecas de cada cultivar de cana-de-açúcar que responde de modo distinto à aplicação do produto. Contrariamente ao relatado neste trabalho, Abd-Alla et al. (2000) reportaram que os herbicidas paraquat e bromoxynil promoveram redução na colonização micorrízica do sistema radicular de Lupinus albus, Vigna sinensis e Phaseolus vulgaris até $40 \mathrm{DAH}$.

A aplicação de herbicidas não interferiu na atividade da enzima fosomonoesterase ácida nas épocas avaliadas (Tabela 5). No entanto, diferenças foram constatadas entre os cultivares aos 7 e 28 DAH. Resultados semelhantes a esses foram encontrados por Machado et al. (2006), ao relatarem a ocorrência de efeitos de cultivares de arroz sobre a atividade da fosfatase ácida e não dos herbicidas testados. O solo rizosférico do cultivar SP80-1816 mostrou maior atividade de fosfomonoesterase ácida nas avaliações aos 7 e 28 DAH. A atividade da fosfatase ácida é maior quanto menor a quantidade de $\mathrm{P}$ disponivel (Gatiboni et al., 2008); assim, pode haver relação inversa entre a velocidade de solubilização de fosfato inorgânico e a atividade da enzima fosfatase, como observado na avaliação aos 7 DAH (Tabela 2). Esses resultados demonstram diferentes interações entre os cultivares e os microrganismos do solo. Essas interações foram também encontradas por Machado \& Furlani (2004) em solos rizosféricos de genótipos de milho. Também em soja, alguns cultivares apresentaram maior atividade de fosfatase no solo rizosférico (Raposo et al., 2004).

Diante do exposto, conclui-se que houve maior colonização micorrízica arbuscular no 
Tabela 3 - Colonização micorrízica arbuscular do sistema radicular do cultivar de cana-de-açúcar SP80-1816 aos 7, 14 e 28 dias após aplicação dos herbicidas (DAH). Viçosa-MG, 2008

\begin{tabular}{|c|c|c|c|}
\hline \multirow{3}{*}{ Herbicida } & \multicolumn{3}{|c|}{ Época } \\
\hline & $7 \mathrm{DAH}^{5 /}$ & $14 \mathrm{DAH}$ & $28 \mathrm{DAH}$ \\
\hline & \multicolumn{3}{|c|}{$(\%)$} \\
\hline Testemunha sem herbicida & $13,75 b^{6 /}$ & $14,75 \mathrm{~b}$ & $25,25 \mathrm{a}$ \\
\hline Trifloxysulfuron-sodium $^{1 /}$ & $20,25 \mathrm{c}$ & $46,25 \mathrm{a}$ & $33,75 \mathrm{~b}$ \\
\hline Ametryn ${ }^{2 /}$ & $21,25 \mathrm{~b}$ & $24,75 \mathrm{~b}$ & $37,75 \mathrm{a}$ \\
\hline Trifloxysulfuron-sodium + ametryn $^{3 /}$ & $19,50 \mathrm{~b}$ & $24,00 \mathrm{~b}$ & $43,75 \mathrm{a}$ \\
\hline Sulfentrazone $^{4 / /}$ & $15,50 \mathrm{~b}$ & $16,00 \mathrm{~b}$ & $31,00 \mathrm{a}$ \\
\hline $\mathrm{CV}(\%)$ & \multicolumn{3}{|c|}{26,71} \\
\hline
\end{tabular}

${ }^{1 /}$ Envoke $^{\circledR}$; ${ }^{2} /$ Metrimex $500 \mathrm{SC}^{\circledR} ;{ }^{3 /}$ Krismat $^{\circledR}$; ${ }^{4 /}$ Boral $500 \mathrm{SC}^{\circledR}$; ${ }^{5 /}$ Dias após aplicação dos herbicidas; ${ }^{6 /}$ Médias seguidas de mesmas letras, nas linhas, não diferem entre si pelo teste de Tukey a $5 \%$ de probabilidade.

Tabela 4 - Colonização micorrízica arbuscular do sistema radicular do cultivar de cana-de-açúcar RB 867515 aos 7, 14 e 28 dias após aplicação dos herbicidas (DAH). Viçosa-MG, 2008

\begin{tabular}{|c|c|c|c|}
\hline \multirow{3}{*}{ Herbicida } & \multicolumn{3}{|c|}{ Época } \\
\hline & $7 \mathrm{DAH}^{\frac{5}{\prime}}$ & $14 \mathrm{DAH}$ & $28 \mathrm{DAH}$ \\
\hline & \multicolumn{3}{|c|}{$(\%)$} \\
\hline Testemunha sem herbicida & $22,50 \mathrm{a}^{6 /}$ & $27,00 \mathrm{a}$ & $16,25 \mathrm{a}$ \\
\hline Trifloxysulfuron-sodium $^{1 /}$ & $21,75 \mathrm{a}$ & $22,75 \mathrm{a}$ & $25,75 \mathrm{a}$ \\
\hline Ametryn $^{2 /}$ & $27,00 \mathrm{~b}$ & $20,75 \mathrm{~b}$ & $50,75 \mathrm{a}$ \\
\hline Trifloxysulfuron-sodium + ametryn $^{3 /}$ & $11,50 \mathrm{~b}$ & $20,50 \mathrm{ab}$ & $22,75 \mathrm{a}$ \\
\hline Sulfentrazone $e^{4 /}$ & $20,75 \mathrm{a}$ & $22,75 \mathrm{a}$ & $27,00 \mathrm{a}$ \\
\hline $\mathrm{CV}(\%)$ & \multicolumn{3}{|c|}{26,67} \\
\hline
\end{tabular}

${ }^{1 /}$ Envoke $^{\circledR} ;{ }^{2 /}$ Metrimex $500 \mathrm{SC}^{\circledR} ;{ }^{3 /}$ Krismat $^{\circledR} ;{ }^{4 /}$ Boral $500 \mathrm{SC}^{\circledR} ;{ }^{5 /}$ Dias após aplicação dos herbicidas; ${ }^{6 /}$ Médias seguidas de mesmas letras, nas linhas, não diferem entre si pelo teste de Tukey a $5 \%$ de probabilidade.

Tabela 5 - Atividade de fosfomonoesterases ácidas de solo rizosférico de cana-de-açúcar, amostrado a $10 \mathrm{~cm}$ de profundidade, em função de cultivares e herbicidas, aos 7, 14 e 28 dias após a aplicação dos herbicidas. Viçosa-MG, 2008

\begin{tabular}{|l|c|c|c|}
\hline \multirow{2}{*}{ Tratamento } & \multicolumn{3}{c|}{ Ativ. fosfatase $\left(\mathrm{mg}\right.$ de $p$-nitrofenol $\mathrm{g}^{-1}$ de solo) } \\
\cline { 2 - 4 } & $7 \mathrm{DAH}^{1 /}$ & $14 \mathrm{DAH}$ & $28 \mathrm{DAH}$ \\
\hline Testemunha sem herbicida & $57,39 \mathrm{a}^{\underline{2}}$ & $45,25 \mathrm{a}$ & $60,55 \mathrm{a}$ \\
\hline Trifloxysulfuron-sodium & $56,90 \mathrm{a}$ & $45,72 \mathrm{a}$ & $61,82 \mathrm{a}$ \\
\hline Ametryn & $54,35 \mathrm{a}$ & $44,96 \mathrm{a}$ & $62,34 \mathrm{a}$ \\
\hline Trifloxysulfuron-sodium + ametryn & $57,12 \mathrm{a}$ & $45,91 \mathrm{a}$ & $60,65 \mathrm{a}$ \\
\hline Sulfentrazone & $60,78 \mathrm{a}$ & $45,94 \mathrm{a}$ & $62,35 \mathrm{a}$ \\
\hline SP 801816 & $60,69 \mathrm{a}$ & $46,07 \mathrm{a}$ & $62,38 \mathrm{a}$ \\
\hline RB 867515 & $53,93 \mathrm{~b}$ & $45,04 \mathrm{a}$ & $60,70 \mathrm{~b}$ \\
\hline CV $\%)$ & 16,11 & 4,12 & 3,03 \\
\hline
\end{tabular}

${ }^{1 /}$ Dias após a aplicação dos tratamentos; ${ }^{2 /}$ Médias seguidas da mesma letra na coluna não diferem entre si pelo teste de Tukey para os tratamentos com herbicidas e $\mathrm{F}$ para os cultivares, ambos a $5 \%$ de probabilidade.

sistema radicular do cultivar RB867515. A aplicação do herbicida trifloxysulfuron-sodium estimula a colonização micorrízica do cultivar SP80-1816. Já a aplicação desse herbicida associado ao herbicida ametryn reduziu a colonização micorrízica logo após a aplicação dos tratamentos para o cultivar RB867515. O herbicida ametryn elevou a colonização 
micorrízica ao longo do tempo para ambos os cultivares; já o sulfentrazone não influenciou essa variável. A atividade da enzima fosfatase ácida foi superior no cultivar SP80-1816, não sendo influenciada pelos herbicidas testados. A colonização micorrízica arbuscular é distinta entre os cultivares de cana-de-açúcar e influenciada de forma diferenciada pelos herbicidas aplicados sobre a cultura.

\section{AGRADECIMENTOS}

Ao Conselho Nacional de Desenvolvimento Científico e Tecnológico (CNPq), pelas concessões de bolsas e apoio financeiro para a realização da pesquisa.

\section{LITERATURA CITADA}

ABD-ALLA, M. H.; OMAR, S. A.; KARANXHA, S. The impact of pesticides on arbuscular mycorrhizal and nitrogenfixing symbioses in legumes. Appl. Soil Ecol., v. 14, n. 3, p. 191-200, 2000.

ANDRADE, S. A. L.; SILVEIRA, A. P. D. Mycorrhiza influence on maize development under $\mathrm{Cd}$ stress and $\mathrm{P}$ supply. Braz. J. Plant Physiol., v. 20, n. 1, p. 39-50, 2008.

BERBARA, R. L. L.; SOUZA, F. A.; FONSECA, H. M. A. C. Fungos micorrízicos arbusculares: muito além da nutrição. In: FERNANDES, M. S. (Org.). Nutrição mineral de plantas. Viçosa, MG: Sociedade Brasileira de Ciência do Solo, 2006. p. $53-88$

BERTIN, C.; YANG, X.; WESTON, L. A. The role of root exudates and allelochemicals in the rhizosphere. Plant Soil, v. 256, n. 1, p. $67-83,2003$

BETHLENFALVAY, G. J. et al. Mycorrhizae, biocides, and biocontrol. Herbicide-mycorrhiza interactions in soybean and cocklebur treated with bentazon. Appl. Soil Ecol., v. 3, n. 2, p. 197-204, 1996.

CARRELHO, R. et al. The effect of different soil properties on arbuscular mycorrhizal colonization of peanuts, sorghum and maize. Acta Bot. Bras., v. 21, n. 3, p. 723-730, 2007.

CHRISTOFFOLETI, P. J. et al. Carfentrazone-ethyl aplicado em pós-emergência para o controle de Ipomea spp. e Commelina benghalensis na cultura da cana-de-açúcar. Planta Daninha, v. 24, n. 1, p. 83-90, 2006.

COMISSÃO DE FERTILIDADE DO SOLO DO ESTADO DE MINAS GERAIS - CFSEMG. Recomendações para o uso de corretivos e fertilizantes em Minas Gerais - 5 aproximação. Viçosa-MG: Universidade Federal de Viçosa, 1999. $359 \mathrm{p}$
COMPANHIA NACIONAL DE ABASTECIMENTO CONAB. Disponível em: < http://www.conab. gov.br/ conabweb/download/safra/3lev-cana.pdf $>$. Acesso em: 10 fev. 2009.

DAWO, M. I.; WILKINSON, J. M.; PILBEAM, D. J. Interactions between plants in intercropped maize and common bean. J. Sci. Food Agric., v. 89, n. 1, p. 41-48, 2009.

EMPRESA BRASILEIRA DE PESQUISA AGROPECUÁRIA - EMBRAPA. Centro Nacional de Pesquisa Agropecuária de Solos. Sistema brasileiro de classificação de solos. Rio de Janeiro: 2006. 412 p.

GATIBONI, L. C. et al. Fósforo da biomassa microbiana e atividade de fosfatases ácidas durante a diminuição do fósforo disponível no solo. Pesq. Agropec. Bras., v. 43, n. 8, p. 1085-1091, 2008 .

GIOVANNETTI, M.; MOSSE, B. An evaluation of techniques for measuring vesicular arbuscular mycorrhizal infection in roots. New Phytol., v. 84, n. 6, p. 489-500, 1980 .

LANDEWEERT, R. et al. Linking plants to rocks ectomycorrhizal fungi mobilize nutrients from minerals. Trends Ecol. Evol., v. 16, n. 5, p. 248-254, 2001.

MACHADO, C. T. T.; FURLANI, A. M .C. Root phosphatase activity, plant growth and phosphorus accumulation of maize genotypes. Sci. Agric., v. 61, n. 2, p. 216-223, 2004.

MACHADO, R. F. et al. Reflexos do mecanismo de ação de herbicidas na qualidade fisiológica de sementes e na atividade enzimática em plântulas de arroz. R. Bras. Sementes, v. 28, n. 3 , p. $151-160,2006$.

MALTY, J. S.; SIQUEIRA, J. O.; MOREIRA, F. M. S Efeitos do glifosato sobre microrganismos simbiotróficos de soja, em meio de cultura e casa de vegetação. Pesq. Agropec. Bras., v. 41, n. 2, p. 285-291, 2006

MIYAUCHI, M. Y. H. et al. Interactions between diazotrophic bacteria and mycorrhizal fungus in maize genotypes. Sci. Agric., v. 65, n. 5, p. 525-531, 2008.

NOVAIS, R. F. et al. Fósforo em solo e planta em condições tropicais. In: NOVAIS, R. F. et al. (Eds.) Fertilidade do solo Viçosa, MG: Sociedade Brasileira de Ciência do Solo, 2007. p. $471-551$

PHILLIPS, J. M.; HAYMAN, D. S. Improved procedures for clearing roots and staining parasitic and vesicular arbuscular mycorrhizal fungi for rapid assessment of infections. Trans. British Mycol. Soc., v. 55, n. 2, p. $158-161,1970$. 
PIRES, F. R. et al. Rhizospheric activity of potentially phytoremediative species for tebuthiuron-contaminated soil R. Bras. Ci. Solo, v. 29, n. 4, p. 627-634, 2005

PRAMANIK, M. H. R. et al. Effect of temperature amd photoperiod on phytotoxic root exudates of cucumber (Cucumis sativus) in hydroponic culture. J. Chem. Ecol., v. 26, n. 8 , p. 1953-1967, 2000.

PROCÓPIO, S. O. et al. Manejo de plantas daninhas na cultura da cana-de-açúcar. Viçosa-MG: Universidade Federal de Viçosa, 2003. 150 p

RAPOSO, R. W. C. et al. Acid phosphatase activity and leaf phosphorus content in soybean cultivars. Sci. Agric., v. 61, n. 4, p. 439-445, 2004.

REIS, M. R. et al. Ação de herbicidas sobre microrganismos solubilizadores de fosfato inorgânico em solo rizosférico de cana-de-açúcar. Planta Daninha, v. 26, n. 2, p. 333-341, 2008.

REIS, V. M.; DE PAULA, M. A.; DÖBEREINER, J. Ocorrência de micorrizas arbusculares e da bactéria diazotrófica acetobacter diazotrophicus em cana-de-açúcar. Pesq. Agropec. Bras., v. 34, n. 10, p. 1933-1941, 1999.

REJON, A. Mycorrhizal fungi influence competition in a wheat-ryegrass association treated with the herbicide diclofop. Appl.Soil Ecol., v. 7, n. 1, p. 51-57, 1997.

RHEINHEIMER, D. S.; GATIBONI, L. C.; KAMINSKI, J. Fatores que afetam a disponibilidade do fósforo e o manejo da adubação fosfatada em solos sob sistema plantio direto.

Ci. Rural, v. 38, n. 4, p. 576-586, 2008.

RODRIGUES, B. N.; ALMEIDA, F. R. Guia de herbicidas 5.ed. Londrina: Edição dos Autores, 2005. 591 p.

SANTOS, J. B. et al. Action of two herbicides on the microbial activity of soil cultivated with common bean (Phaseolus vulgaris) in conventional-till and no-till systems. Eur. Weed Res Soc., v. 46, n. 4, p. 284-289, 2006.

SHENG, M. Influence of arbuscular mycorrhizae on photosynthesis and water status of maize plants under salt stress. Mycorrhiza, v. 18, n. 6/7, p. 287-296, 2008.
SILVA, A. A. et al. Herbicidas: classificação e mecanismo de ação. In: SILVA, A. A.; SILVA, J. F. (Eds.). Tópicos em manejo de plantas daninhas. Viçosa, $\mathrm{MG}$ : Universidade Federal de Viçosa, 2007. 367 p.

\section{SINDICATO NACIONAL DA INDÚSTRIA DE} PRODUTOS PARA DEFESA AGRÍCOLA - SINDAG. Disponível em: $<\mathrm{http}$ ://www.sindag.com.br/conexao/ anteriores/conexao5_mar08.pdf $>$. Acesso em: $10 \mathrm{de} \mathrm{fev.} \mathrm{de}$ 2009.

SIQUEIRA, J. O.; POUYÚ, E.; MOREIRA, F. M. S. Micorrizas arbusculares no crescimento pós-transplantio de mudas de árvores em solos com excesso de metais pesados.

R. Bras. Ci. Solo, v. 23, n. 5, p. 569-580, 1999

SIQUEIRA, J. O.; ANDRADE, A. T.; FAQUIN, V. O papel dos microrganismos na disponibilização e aquisição de fósforo pelas plantas. In: YAMADA, T;; ABDALLA, S. R. S. (Eds.) Fósforo na agricultura brasileira. Piracicaba: ESALQ/USP, 2004. p. $117-156$.

SOARES, C. R. F. S. et al. Micorriza arbuscular e nutrição fosfática na toxidez de zinco para a trema [Trema micrantha (1.) blum.]. R. Bras. Ci. Solo, v. 30, n. 4, p. 665-675, 2006.

SYLVIA, D. M. Mycorrhizal symbioses. In: SYLVIA, D. M. et al (Eds.) Principles and applications of soil microbiology. 2.ed. New Jersey: 2005. 645 p.

TABATABAI, M. A.; BREMMER, J. M. Use of p-nitrophenyl phosphate for assay of soil phosphatase activity, Soil Biol. Biochem., v. 1, n. 4, p. 301-307, 1969.

TIRONI, S. P. et al. Ação de herbicidas na atividade de bactérias solubilizadoras de fosfato de rizosfera de cana-deaçúcar. Planta Daninha, v. 27, n. 4, p. 747-754, 2009

VIEIRA, R. F.; SILVA, C. M. M. S.; SILVEIRA, A. P. D. Soil microbial biomass $\mathrm{C}$ and symbiotic processes associated with soybean after sulfentrazone herbicide application. Plant Soil, v. 300, n. 1, p. 95-103, 2007.

VIVIAN, R. et al. Persistência de sulfentrazone em Latossolo vermelho-amarelo cultivado com cana-de-açúcar.

Planta Daninha, v. 24, n. 4, p. 741-750, 2006 